\title{
Hospital Reputation and Perceptions of Patient Safety
}

\author{
José Joaquín Mira ${ }^{a}$ b Susana Lorenzo ${ }^{c}$ Isabel Navarro ${ }^{b}$ \\ ${ }^{a}$ Departamento Salud San Juan-Alicante, Conselleria de Sanitat, Alicante, ${ }^{b}$ Universidad Miguel Hernández, Elche, and \\ 'Hospital Universitario Fundación Alcorcón, Madrid, Spain
}

\section{Key Words}

Patient safety · Management · Quality assurance

\begin{abstract}
Objective: The objective of this study was to explore the theoretical relationship between the social reputation and the perceived safety of a hospital. Subjects and Methods: A random sample of 316 patients and 27 relatives of patients who were unable to respond themselves at four public hospitals in Madrid, Barcelona and Alicante were interviewed to establish a measure of reputation and perceived safety. Results: There were no different perceptions between patients and relatives regarding hospital reputation or safety perception ( $p>0.05)$. The perception of patients or relatives of health professionals' competence ( $\beta=0.07,95 \% \mathrm{Cl} 0.01-0.12)$, the perception of a positive treatment output of surgical or medical treatment $(\beta=0.35,95 \% \mathrm{Cl} 0.22-0.49)$ and hospital reputation ( $\beta=0.08,95 \% \mathrm{Cl} 0.02-0.14$ ) were directly and positively associated with their perception that the hospital was a safe clinical environment in which few clinical errors are committed. Conclusions: The data suggested that the social reputation of these hospitals and the perceptions of patients or relatives of patient safety were indeed correlated. Future research should assess whether efforts to enhance hospital reputation, by improving patients' perceptions of clinical safety, may contribute to reducing the frequency of litigation cases.

(c) 2013 S. Karger AG, Basel
\end{abstract}

\section{Introduction}

The reputation of an organization is based on how it is perceived by clients, employees, suppliers and the general public. There is a tradition of assessing the reputation of hospitals from the professionals' viewpoint [1]. However, to date relatively little research has been conducted on the reputation of hospitals from the patients' or relatives' viewpoint. This research is relevant because some recent studies have suggested that reputation is associated with better clinical care results [2] and with higher-quality scientific production [3]. Hospital reputation acts also as a shield against litigation, and it may help the hospital to attract and retain talented professionals $[2,4]$. In the absence of relevant information to guide patients' choices of a health care provider or hospital, decisions are frequently made on reputation [5]. Reputation is based on clients', employees' and suppliers' perceptions of an organization. It is a social asset which should be appropriately managed so that it can be turned into an advantage for the organization [6]. Reputation is the sum of a set of attributes assigned to an organization [7]. These attributes include the quality of the product or service, confidence, ethical conduct, management and leadership, social responsibility (vis-à-vis economic, person-related and environmental aspects) and biomedical innovation and research [6]. An organization's reputation has also been associated with higher quality ratings for its products [4].

\begin{tabular}{ll}
\hline KARGER & $\begin{array}{l}\text { () 2013 S. Karger AG, Basel } \\
1011-7571 / 14 / 0231-0092 \$ 39.50 / 0 \quad \text { Karger }\end{array}$ \\
$\begin{array}{l}\text { E-Mail karger@karger.com } \\
\text { www.karger.com/mpp }\end{array}$ & $\begin{array}{l}\text { This is an Open Access article licensed under the terms of the } \\
\text { Creative Commons Attribution-NonCommercial 3.0 Un- } \\
\text { ported license (CC BY-NC) (www.karger.com/OA-license), } \\
\text { applicable to the online version of the article only. Distribu- } \\
\text { tion permitted for non-commercial purposes only. }\end{array}$
\end{tabular}

José Joaquín Mira

Universidad Miguel Hernandez, Edificio Altamira

Avd Universidad $\mathrm{s} / \mathrm{n}$

ES-03202 Elche (Spain)

E-Mail jose.mira@umh.es 
Table 1. The predictive capacity of reputation on patient perception of safety

\begin{tabular}{lllllll}
\hline Factor & Beta & $95 \%$ CI & $\begin{array}{l}\beta \\
\text { standardized }\end{array}$ & t & p & $\begin{array}{l}\text { Collinearity } \\
\text { index }\end{array}$ \\
\hline Confidence in the hospital's professionals & 0.07 & $0.01-0.12$ & 0.15 & 2.5 & 0.01 & 1.9 \\
Hospital's good reputation & 0.08 & $0.02-0.14$ & 0.13 & 2.5 & 0.01 & 1.3 \\
Positive perception of the treatment results & 0.35 & $0.22-0.49$ & 0.32 & 5.1 & 0.001 & 1.7 \\
\hline
\end{tabular}

In theory there should be an association between reputation and patients' perceptions of patient safety in the clinical setting; however, up to date the association between the two constructs has not been studied. The objective of this study was to explore the relationship between a hospital's social reputation and perceptions of whether it provides a safe clinical environment.

\section{Subjects and Methods}

In a project funded by the FIS (Spanish Health Research Fund) and the ERDF (European Regional Development Fund), our group developed and validated a hospital reputation scale. In this project we explored the theoretical relationship between the social reputation of a hospital and the patients' perceptions of the hospital's safety. As a measure of hospital reputation three questions were assessed: whether or not the hospital was well thought of by the patients, their confidence in the hospital's professionals, and their rating of the outcomes of clinical or surgical interventions. The frequency with which, from the patients' or relatives' view, clinical errors were committed at that hospital was used as a measure of the perceived safety. We applied multiple regression analysis to ascertain the direction of these relations, considering as factors the measure of hospital social reputation and as dependent variable the measure of perceived safety. This study was conducted as part of a larger project to develop a reputation index for hospitals, which will make it possible to rate hospitals based on scores of 4 dimensions and 12 components of social reputation.

The measure of the factors included in the model was obtained by recording the opinions of a random sample of 316 patients and 27 accompanying relatives of patients unable to respond themselves who attended one of the four collaborating hospitals in Madrid (University Hospital of Alcorcón), Barcelona (Hospital Doctor Moisés Broggi) and Alicante (University Hospital of Alicante and University Hospital of San Juan-Alicante) for consultation with their doctor. They were interviewed while they were in the waiting room by a nurse (Madrid), a social worker (Barcelona) or a psychologist (Alicante) who were trained to conduct these interviews. The sample size was calculated with the ENE 3.0. software (GlaxoSmithKline, Madrid, Spain), for an error of 5\% and with $\mathrm{p}=\mathrm{q}=0.50$. We used the Statistical Package for the Social Sciences (version 19.0; SPSS, Inc., Chicago, Ill., USA) for this analysis.

Hospital Reputation and Perceptions of Patient Safety

\section{Results}

The majority of those who responded were outpatients. A total of $26(7.6 \%)$ of the patients and 4 (12.9\%) of the accompanying relatives of the patients unable to respond themselves refused to answer the interviewer's questions. There were no different perceptions between patients and relatives regarding hospital reputation or safety perception $(\mathrm{p}>0.05)$. So, all data were analyzed together.

The results of this analysis led to a model with the set of factors that offered a satisfactory solution $\left(\mathrm{R}^{2}=25 \%\right.$, $\mathrm{F}=36.2, \mathrm{p}<0.001)$, confirming the predictive capacity of the factors included in the equation (table 1). The hospital's reputation, the confidence in the professionals and the perception of positive treatment results were associated with the perceptions of the relatives accompanying the patients of a low number of errors and patient safety incidents. We found that an additional point in the confidence in the health professionals perceived by the patients increased by $15 \%$ the results on the scores of the hospital as a safety setting. In the same way, increasing the hospital's reputation or the positive perception of the treatment results led to a 13 and $15 \%$ increase of the safety perception, respectively. The perception of the role of managers $(p=0.51)$ and the number and the maintenance of clinical equipment $(p=0.73)$ were not related to the perception of patient safety.

\section{Discussion}

Our findings suggested that when a hospital had a higher reputation, patients and relatives also thought that the institution offered a safer clinical environment. Given the increasing public awareness of clinical errors [8], these results yielded some cues to protect the social image of the hospital. For example, improving the reputation of 
a hospital can cushion the negative effect that adverse events with severe consequences can have on the perception of patients. Three factors in our study, 'confidence in the competence of professionals', 'belief that the treatments applied at the hospital had the desired results' and 'the hospital's good reputation', were directly and positively associated with the perception that the hospital was a safe clinical environment where the patients and the relatives thought few clinical errors are committed. Our findings have offered additional support of the value of the reputation as reported previously [2]. Now, we have some findings which also establish a relationship between reputation and safety.

Our study has several limitations. Spain has a National Health System model. So, patients are usually assigned to a hospital based on their address or their geographical proximity. Hence, we could not establish whether the patients or their family members in our study had suffered an adverse event in the past, and to what degree this might have affected their answers on reputation or their perceptions of the safety of care at the institution. Future research is needed to determine whether improving the social reputation of a hospital and enhanced perceptions of the institution providing a safe environment for care would result in a reduction in litigation cases.

\section{Conclusion}

The study results suggested that the hospitals' social reputation and the perceptions of the patients and their relatives of patient safety were related.

\section{Acknowledgment}

This study was funded by the FIS (Spanish Health Research Fund) and the ERDF (European Regional Development Fund), reference PS09/00802.

\section{References}

$>1$ Sehgal AR: The role of reputation in U.S. News \& World Report's rankings of the top 50 American hospitals. Annu Intern Med 2010; 152:521-525.

$>2$ Hibbard JH, Jewett JJ: Will quality report cards help consumers? Health Aff 1997;16: 218-228.

$>3$ Asenjo MA, Bertrán MJ, Guinovart C, et al: Analysis of Spanish hospital's reputation: relationship with their scientific production in different subspecialities. Med Clin (Barc) 2006; 126:768-770.
4 Hibbard JH, Stockard J, Tusler M: Hospital performance reports: impact on quality, market share, and reputation. Health Aff 2005;24: 1150-1160.

5 Dijs-Elsinga J, Otten W, Versluijs MM, et al: Choosing a hospital for surgery: the importance of information on quality of care. Med Decis Making 2010;30:544-555.
6 Withrow SC: The 8 dimensions of quality. Healthcare financial management. Healthc Financ Manage 2006;60:86-91.

$>7$ Șatir Ç: The nature of corporate reputation and the measurement of reputation components. An empirical study within a hospital. Corporate Commun Int J 2006;11:56-63.

$>8$ Oyebode F: Clinical errors and medical negligence. Med Princ Pract 2013;22:323-333. 